\title{
Melatonin inhibits the sphingosine kinase 1/sphingosine-1- phosphate signaling pathway in rabbits with fulminant hepatitis of viral origin
}

\begin{tabular}{|c|c|}
\hline Journal: & Journal of Pineal Research \\
\hline Manuscript ID & JPI-OM-02-16-0043.R1 \\
\hline Manuscript Type: & Original Manuscript \\
\hline Date Submitted by the Author: & $\mathrm{n} / \mathrm{a}$ \\
\hline Complete List of Authors: & $\begin{array}{l}\text { Crespo, Irene; Centro de Investigación Biomédica en Red de } \\
\text { Enfermedades Hepáticas y Digestivas (CIBERehd), Spain ; Centro de } \\
\text { Investigación Biomédica en Red de Enfermedades Hepáticas y Digestivas } \\
\text { (CIBERehd), Spain } \\
\text { SanMiguel, Beatriz; Institute of Biomedicine (IBIOMED), University of } \\
\text { León; Centro de Investigación Biomédica en Red de Enfermedades } \\
\text { Hepáticas y Digestivas (CIBERehd), Spain } \\
\text { Sánchez , Diana Isabel; Institute of Biomedicine (IBIOMED), University of } \\
\text { León, } \\
\text { González, Bárbara; Institute of Biomedicine (IBIOMED), University of León, } \\
\text { Alvarez, Marcelino; University of León, Department of Animal health } \\
\text { Gonzalez-Gallego, J.; Institute of Biomedicine (IBIOMED), University of } \\
\text { León; Centro de Investigación Biomédica en Red de Enfermedades } \\
\text { Hepáticas y Digestivas (CIBERehd), Spain } \\
\text { Tuñon, Maria J; Institute of Biomedicine (IBIOMED), University of } \\
\text { León; Centro de Investigación Biomédica en Red de Enfermedades } \\
\text { Hepáticas y Digestivas (CIBERehd), Spain }\end{array}$ \\
\hline Keywords: & $\begin{array}{l}\text { liver, sphingosine kinase } 1 \text {, sphingosine-1-phosphate, acute liver failure, } \\
\text { melatonin }\end{array}$ \\
\hline
\end{tabular}




\title{
Melatonin inhibits the sphingosine kinase 1/sphingosine-1-phosphate signaling pathway in rabbits with fulminant hepatitis of viral origin
}

\author{
Irene Crespo ${ }^{1,2}$, Beatriz San-Miguel ${ }^{1,2}$, Diana I Sánchez ${ }^{1}$, Bárbara González-Fernández ${ }^{1}$, \\ Marcelino Álvarez ${ }^{3}$, Javier González-Gallego ${ }^{1,2}$, and María J. Tuñón ${ }^{1,2}$ \\ ${ }^{1}$ Institute of Biomedicine (IBIOMED), University of León, ${ }^{2}$ Centro de Investigación Biomédica en \\ Red de Enfermedades Hepáticas y Digestivas (CIBERehd), Spain, ${ }^{3}$ Department of Animal Health, \\ University of León, León, Spain.
}

Running head: Sphingosine kinase 1/sphingosine-1-phosphate pathway and melatonin

Address reprint requests to María J. Tuñón, PhD, Institute of Biomedicine, University of León, 24071-León, Spain. Phone: +34 987 291261; Fax: +34 987 291267. E-mail: mjtung@unileon.es

Key words: liver, sphingosine kinase 1, sphingosine-1-phosphate, acute liver failure, melatonin 


\begin{abstract}
The sphingosine kinase (SphK)1/sphingosine-1-phosphate (S1P) pathway is involved in multiple biological processes, including liver diseases. This study investigate whether modulation of the SphK1/S1P system associates to the beneficial effects of melatonin in an animal model of acute liver failure (ALF) induced by the rabbit hemorrhagic disease virus (RHDV). Rabbits were experimentally infected with $2 \times 10^{4}$ hemagglutination units of a RHDV isolate and received 20 $\mathrm{mg} / \mathrm{kg}$ of melatonin at $0 \mathrm{hr}, 12 \mathrm{hr}$ and $24 \mathrm{hr}$ postinfection. Liver mRNA levels, protein concentration and immunohistochemical labelling for SphK1 increased in RHDV-infected rabbits. S1P production and protein expression of the S1PR1 receptor were significantly elevated following RHDV infection. These effects were significantly reduced by melatonin. Rabbits also exhibited increased expression of toll-like receptor (TLR)4, tumor necrosis factor alpha (TNF- $\alpha$ ), interleukin (IL)-6, nuclear factor-kappa B (NF-кB) p50 and p65 subunits and phosphorylated inhibitor of kappa

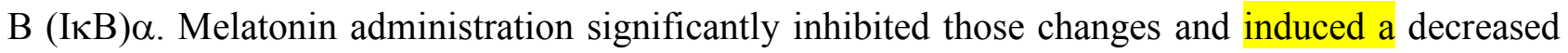
immunoreactivity for RHDV viral VP60 antigen in the liver. Results obtained indicate that the SphK1/S1P system activates in parallel to viral replication and the inflammatory process induced by the virus. Inhibition of the lipid signaling pathway by the indole reveals novel molecular pathways that may account for the protective effect of melatonin in this animal model of ALF, and supports the potential of melatonin as an antiviral agent.
\end{abstract}


Introduction

Sphingolipids represent a major class of lipids that form components of cellular membranes and play important roles in diverse cellular events, such as cell growth arrest, senescence, apoptosis, or inflammation [1]. Sphingosine-1-phosphate (S1P), a pleiotropic bioactive lipid mediator, is formed by the phosphorylation of sphingosine by sphingosine kinases (SphK) and regulates an array of biological activities in various cell types [2]. Two isoforms of mammalian SphK (SphK1 and SphK2) have been cloned and characterized. SphK1, the predominant isoform in many cells, plays a central role in the so-called 'sphingolipid rheostat' as it controls the balance between the levels of the sphingolipids ceramide, sphingosine, and S1P [3]. Different stimuli activate SphK1 by inducing its phosphorylation and translocation to the plasma membrane, where S1P is produced [4]. Most of the characterized actions of S1P are mediated through a family of five G protein-coupled receptors (S1PR types 1-5) [5]. S1PR1, S1PR2, and S1PR3 are expressed by a wide variety of tissues, while S1PR4 expression is confined to lymphoid and haematopoietic tissue and S1PR5 expression to the central nervous system [6]. Tumor necrosis factor (TNF) $\alpha$-dependent activation of SphK1 and binding of S1P to S1PR1 receptor, has been reported to promote nuclear factor-kappa $\mathrm{B}(\mathrm{NF}-\kappa \mathrm{B})$ activation and signal transducer and activator of transcription 3 (STAT3)-mediated interleukin (IL)6 formation, contributing to a feed-forward amplification loop which plays an important role in inflammation and cancer $[4,7]$.

In the last few years a number of studies have approached the biological significance of the SphK1/S1P signalling pathway in liver diseases. A role of S1P receptors has been reported in the wound healing response to liver injury induced by carbon tetrachloride and in cholestasis-induced liver fibrosis, respectively [8,9]. It has been shown that S1P plays a significant role in regeneration 
and fibrosis in diethylnitrosamine-treated mice [10], and that intracellular S1P contributes to collagen expression of hepatic miofibroblasts in human fibrosis [11]. SphK1 also mediates inflammation in nonalcoholic fatty liver disease [12] and it has been very recently reported that deletion of SphK1 ameliorates hepatic steatosis in obese mice [13]. Acute liver failure (ALF) is an unusual, severe and often fatal, condition resulting of rapid hepatocyte injury occurring over days or a few weeks, and encompassing multiple etiologies. Liver transplantation is the only therapy of proven benefit, but the rapidity of progression and the variable course of the disease limit its use [14]. Therefore, identification of new molecular targets may be useful in AFL therapy. However, the exact functional role of $\mathrm{S} 1 \mathrm{P}$ as well as the therapeutic potential of strategies aimed at SphK1/S1P signalling in AFL is still unknown.

Viral infections due to hepatitis B virus, hepatitis A virus, and hepatitis E virus are common causes of ALF, mainly in particular geographical areas of the world [15]. Recently, several studies have addressed the role of S1P in viral infections and shown that bovine viral diarrhea virus [16] or dengue virus [17] inhibit SphK1 activity, leading to enhanced virus replication. In contrast, respiratory syncytial virus [18], human cytomegalovirus [19], and influenza virus [3,20] increase the activation of SphK1. Therefore, SphK1 activity is differentially regulated depending on the type of virus, presumably because viruses have developed specialized strategies to employ host cellular machinery for their own advantage [21,22]. Our research group has described a new animal model of ALF using experimental infection of rabbits with the rabbit hemorrhagic disease virus (RHDV) which reproduces the most representative biochemical and histologic parameters and clinical signs of the human disease $[23,24]$. Different studies with the RHDV have demonstrated that melatonin reduces liver damage in RHDV-infected rabbits by a combination of anti-oxidant, antiinflammatory and anti-apoptotic effects, being also able to reduce viral replication [25-28]. However, information on the relationship between melatonin and sphingolipid metabolism is 
scarce, and only one research indicating an association of melatonin with SphK1 inhibition in prostate cancer cells has been published until now [29]. In the present work we first investigated if RHDV infection induces changes in the SphK1/S1P signalling pathway. Subsequently, the potential contribution of this system to the protective effects of melatonin was analysed. Results obtained support the usefulness of melatonin as an antiviral agent and the interest of the SphK1/S1P system as an attractive target for therapeutic interventions in AFL.

\section{Materials and methods}

\section{Virus and experimental model}

Nine-week-old male New Zealand white rabbits were kept in the animal facility of the University of León with $12-\mathrm{hr}$ light cycle at $21-22^{\circ} \mathrm{C}$ and $50 \%$ relative humidity. They were given a standard dry rabbit food and water ad libitum. Effects of melatonin were studied by sacrificing control rabbits and batches of infected animals at 18, 24, 30 and $36 \mathrm{hr}$ post infection (hpi). Infection was induced by i.m. injection of $2 \times 10^{4}$ hemagglutination units of an RHDV isolate [23]. Melatonin was given (20 mg/kg body weight i.p.) at 0, 12 and $24 \mathrm{hpi}$; untreated animals received $4 \mathrm{~mL}$ of vehicle at 0,12 and 24 hpi. Melatonin (Sigma, St Louis, MO, USA) was dissolved into absolute ethanol and further dilutions were made in saline. The final concentration of ethanol was $5 \%$.

The study was carried out in strict accordance with the recommendations in the Guide for the Care and Use of Laboratory Animals of the National Institutes of Health, and was specifically approved by the Ethics Committee of the University of León.

\section{Real-time RT-PCR}

Total RNA was extracted from frozen rabbit liver using a Trizol reagent (Life Technologies, Madrid, Spain) and quantified using NANO DROP 1000 spectrophotometer (Thermo Scientific, 


\begin{abstract}
Wilmington, DE). Residual genomic DNA was removed by incubating RNA with RQ1 RNase-free DNase (Promega, Madison, WI). RNA integrity was confirmed by formaldehyde gel electrophoresis. Total RNA $(1 \mu \mathrm{g})$ was reverse transcribed as described [30] and mRNA was determined by real time PCR analysis using SYBR Green I Master (Roche Diagnostics GmbH, Mannheim, Germany) and the appropriate primers (5'-GCTGGCCGCTTCTCTGAAC-3' and 5'GCTGGCCGCTTCTCTGAAC-3' for SphK1 and 5'-TGGCATCCTGACGCTCAA-3'and 5'TCGTCCCAGTTGGTCACGAT-3' for $\beta$-Actin). Relative changes in gene expression levels were determined using the $2^{-\Delta \Delta \mathrm{ct}}$ method as described [25]. The cycle number at which the transcripts were detectable $(\mathrm{Ct})$ was normalized to the cycle number of $\beta$-Actin gene detection, referred to as $\Delta \mathrm{Ct}$.
\end{abstract}

\title{
Western blot analysis
}

For Western blot analysis liver tissue (0,2 gr) was homogenised in $1 \mathrm{~mL}$ RIPA buffer containing protease and phosphatase inhibitor cocktails (Roche Diagnostics GmbH), maintaining temperature at $4^{\circ} \mathrm{C}$ throughout all procedures. Then the homogenate was incubated on ice for 30 min and finally the samples were centrifuged at $13,000 \mathrm{~g}$ for $30 \mathrm{~min}$ at $4^{\circ} \mathrm{C}$. The supernatant fraction was stored at $80^{\circ} \mathrm{C}$ in aliquots until use. Protein concentration was measured by Bradford assay. Equal amounts of protein extracts $(30 \mu \mathrm{g})$ were separated by $7-12 \%$ sodium dodecyl sulphate (SDS)polyacrylamide gel electrophoresis and transferred electrically to polyvinyllidene difluoride membranes (Millipore; Bedford, MA, USA). The membranes were then blocked with 5\% non-fat dry milk in Tris-buffered saline containing $0.05 \%$ Tween 20 (TBST) for $30 \mathrm{~min}$ at $37^{\circ} \mathrm{C}$ and probed overnight at $4^{\circ} \mathrm{C}$ with polyclonal anti p50, p65 (Santa Cruz Biotechnology, Santa Cruz, CA, USA),

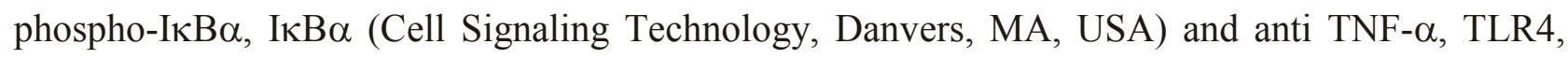


IL-6, SphK1 and S1PR1 (Abcam; Cambridge, UK) antibodies at 1:200-1:1,000 dilution with PBST containing 2.5\% non-fat dry milk. Equal loading of protein was demonstrated by probing the membranes with a rabbit anti Actin polyclonal antibody (1:2,000; Sigma). After washing with TBST, the membranes were incubated for $1 \mathrm{hr}$ at room temperature with secondary HRP conjugated antibody (Dako, Glostrup, Denmark, 1:5,000), and visualized using ECL detection kit (Amersham Pharmacia; Uppsala, Sweden) [26]. The density of the specific bands was quantified with an imaging densitometer (Scion Image J Software 1.46a; Bethesda, MD, USA).

\section{Immunohistochemistry}

Tissue samples were recovered, fixed in 10\% buffered formalin and embedded in paraffin. Sections (4 $\mu \mathrm{m})$ were dewaxed and hydrated through graded ethanol, cooked in $25 \mathrm{mM}$ citrate buffer, $\mathrm{pH}$ 6.0, in a pressure cooker for $10 \mathrm{~min}$, transferred into boiling deionized water and let to cool for 20 min. Tissue sections were then treated with $3 \%$ hydrogen peroxide to inactivate endogenous peroxidase activity. The slides were incubated with rabbit anti SphK1, S1PR1 (Abcam), and mouse anti-VP60 (Ingenasa, Madrid, Spain) antibodies overnight at $4^{\circ} \mathrm{C}$. Subsequently, the sections were incubated for 30 min using the EnVision+ system and developed with a solution of 3-3diaminobenzidine (DAB) (Vector Lab; Burlingame, CA, USA). The slides were stained with hematoxylin for $10 \mathrm{~s}$ and mounted. The specificity of the technique was evaluated by negative controls (omitting the incubation with the primary antibody and incubating it with non-immune sera). Pathological findings were assessed by one of the authors blinded to the group allocations.

\section{Assay for S1P levels}

Journal of Pineal Research 
S1P was tested by ELISA using a commercial kit (Echelon Biosciences, UT, USA). Quantitative S1P assays were done in duplicate on all liver homogenate samples according to manufacturer's instructions. The levels were expressed as $\mathrm{pmol} / \mu \mathrm{g}$ of protein.

\section{Results}

In order to confirm if the SphK1/S1P axis was induced in RHDV-infected rabbits, immunohistochemistry for SphK1 was performed. Immunoreactivity was negative in liver sections from control rabbits, and increased progressively in the RHDV-infected group (Fig. 1A, B). Parallel changes were observed in the mRNA levels and protein concentration of the enzyme (Fig. 1C, D). All these effects were significantly abrogated in animals receiving melatonin (Fig. 1A-D).

To investigate whether RHDV-induced SphK1 activation increases intracellular S1P (the product of SphK1), S1P was tested by ELISA at several time points after RHDV infection. Our data indicate that RHDV infection significantly increased the level of S1P in rabbit liver (Fig. 2D). However, melatonin administration significantly dampened the elevation of S1P level.

Since binding of S1P to the S1PR1 receptor has been shown to be playing a role in the activation of inflammatory pathways, we first investigated whether this receptor is expressed in rabbit cells. Western blot analysis indicated that S1PR1 was detectable in control rabbits and its expression increased significantly in animals infected with the RHDV (Fig. 2C). This issue was further confirmed by S1PR1 immunohistochemical labelling (Fig. 2A, B). Protein concentration and immunoreactivity were significantly lower in animals treated with melatonin (Fig. 2A-C).

Given the well-known role of the SphK1/S1P system on inflammation, expression of different inflammatory markers was studied in RHDV-infected and melatonin-treated rabbits. As shown in Fig.3 expression of TNF- $\alpha$ and IL-6 was significantly elevated in infected rabbits and this effect 
associated to an increased expression of TLR4. Changes in the NF- $\kappa$ B-mediated signalling pathway were shown by a significant increase in the concentration of p50 and p65 NF- $\mathrm{BB}$ subunits, a reduced expression of $\mathrm{I} \kappa \mathrm{B} \alpha$, and an enhanced phosphorylation of the inhibitor. These effects were significantly attenuated in rabbits treated with melatonin.

Finally, to analyse the relationship between changes in the SphK1/S1P pathway and viral replication, the presence of the virus in the liver of RHDV-infected rabbits was detected by immunohistochemical staining of the viral VP60 antigen. Results obtained show a progressive increase in the extent of labelling in RHDV-infected animals. Decreased immunoreactivity in rabbits treated with melatonin confirms the inhibitory role of the indol on RHDV replication (Fig. $4 \mathrm{~A}, \mathrm{~B})$.

\section{Discussion}

$\mathrm{S} 1 \mathrm{P}$ is now recognized as a powerful mediator of many vital cellular processes, and a pletora of roles have emerged in the regulation of phenomena as inflammation or viral replication. The development of the sphingosine analogue FTY720 has proven the potential beneficial effects of targeting SphK1/S1P signaling in human diseases and the interest of developing a sphingolipidcentered therapeutics [31]. Mechanisms responsible for liver injury in acute severe hepatitis leading to AFL are complex and include the virus cytopatic effect, the damage induced by an exacerbated immune response, and the citotoxicty of immune effectors [32]. The development by our group of a highly reproducible model of virus-induced ALF has offered a valuable tool to test protective therapies in this condition and to identify the responsible mechanisms [33]. Previous studies have shown that in rabbits with fulminant hepatitis induced by the RHDV a combination of effects contribute to reduce liver damage [25-27]. Data obtained in the present research indicate that 
inhibition of SphK1/S1P signaling may be a novel mechanism contributing to the benefits of melatonin treatment in this animal model of ALF.

S1P has been linked to the production of proinflammatory cytokines and inflammation, and different research suggests that pharmacological agents targeting the function of S1P and its receptors show therapeutic potential for treating a wide range of inflammatory disorders [4,7]. We demonstrate in our study that hepatic SphK1 activity is upregulated in RHDV-infected rabbits, with an increased production of S1P and enhanced protein level of S1PR1, which associate to a higher TNF- $\alpha$ and IL-6 expression. Melatonin significantly reduced, as previously reported [34], expression of the proinflammatory markers, and also resulted in a clear inhibition of the SphK1/S1P system. Some studies have shown that suppression of the SphK1/S1P pathway contributes to the anti-inflammatory effect of different therapeutic agents. Thus, the flavone apigenin decreases serum levels of IL-1 $\beta$, IL-6 and TNF- $\alpha$ in a lipopolysaccharide-induced endotoxemic rat model, and this effect relates to a lowered SphK1 activity and S1P level in heart; in addition, apigenin also inhibits the SphK1/S1P system, resulting in a lowered inflammatory response, in rat embryonic heartderived H9c2 cells [35]. In murine models of inflammatory arthritis, chemical inhibition or siRNA knockdown of SphK1 results in reduced inflammation [36]. The synthetic sphingosine analog FTY720 phosphate, by binding to and inducing functional antagonism of the S1PR1, reduces proinflammatory cytokine release by astrocytes in mice with multiple sclerosis [37].

$\mathrm{NF}-\kappa \mathrm{B}$ is a transcription factor acting as a known pleiotropic regulator of various genes involved in inflammatory responses. Many biological stimuli result in the phosphorylation and degradation of the I $\kappa \mathrm{B} \alpha$ inhibitor, causing the nuclear translocation of NF- $\kappa \mathrm{B}$ heterodimers to the nucleus [38]. SphK1 and S1P are necessary for the phosphorylation of IKB $\alpha$ and IKK $\alpha$, an upstream regulator of $\mathrm{I} \kappa \mathrm{B} \alpha$ degradation, leading to $\mathrm{NF}-\kappa \mathrm{B}$ activation, which has therefore been 
proposed to be crucial for connecting the activated SphK1/S1P signaling pathway with inflammation [39]. High fructose feeding in rats or stimulation of BRL3A cells with fructose induces an elevation of SphK1 activity and S1P production, with a subsequent increased phosphorylation of $\mathrm{I} \kappa \mathrm{B} \alpha$ and IKK $\alpha, \mathrm{NF}-\kappa \mathrm{B}$ activation, and increase of IL-1 $\beta$, IL-6 and TNF- $\alpha$ protein levels; inhibition of the ShpK1/S1P pathway by morin, results in a reduction of NF- $\kappa \mathrm{B}$ activation and pro-inflammatory cytokine levels in both experimental models [40]. Glabridin has been shown to inhibit TNF- $\alpha$-induced ICAM-1 expression in HUVEC cells by blocking SphK1 activity and S1P generation, an effect associated to $\mathrm{I} \kappa \mathrm{B} \alpha$ phosphorylation and NF- $\mathrm{B}$ activation [41]. In addition, experimental diabetic nephropathy models, berberine inhibits SphK1 activity and S1P production, also suppressing NF- $\kappa$ B activation [42]. Our finding of a parallel inhibition of the

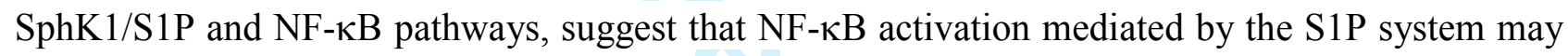
play role in the protective effect of the flavonoid on hepatic inflammation. Moreover, melatonin action could also be connected to the observed downregulation of TLR4, a transmembrane protein which may ignite cascades of proinflammatory mediators, thus aggravating hepatocellular damage in severe forms of acute liver disease [34,43]. Previous studies have shown that lipopolysaccharide stimulation of TLR4 in macrophages increases SphK1 mRNA and activity, resulting in generation of S1P [44], and blockade of SphK1 has been found to inhibit TLR-induced NF-אB activation and production of proinflammatory cytokines in septic mice [45].

Understanding of the role of sphingolipids at the level of viral pathogenicity is still in its infancy and may vary considerably depending on the virus and type of disease [22]. Nevertheless, a number of studies have addressed in the last years the roles of SphK1 in viral infection. Stimulation of SphK1 activity is associated with increased viral replication and cell survival of syncytial virus, human cytomegalovirus or influenza virus [20,46]. However, reduction in SphK1 activity is 
required for successful viral infection by the bovine viral diarrhea virus, and in dengue virus it has been suggested that therapeutic inhibition may have dual befits in the disease by reducing production of inflammatory mediators and assisting clearance of virus-infected cells $[16,46]$. We have previously reported that melatonin reduces VP60 immunohistochemical labelling and VP60 mRNA expression in hepatocytes from RHDV-infected rabbits [27]. Data from the present study confirm a decreased presence of the viral protein VP60 in the liver. In cells infected with the measles virus it has been previously shown that SphK1 inhibition impairs viral protein expression and infectious viral production, being this effect mediated by modulation of the NF- $\mathrm{B}$ signal pathway, because the use of NF- $\kappa$ B specific inhibitors blocks viral replication [47]. It is also known that influenza virus increases expression/activation of SphK1 and inhibition of the enzyme suppresses the activation of NF- $\mathrm{KB}$ to reduce viral RNA synthesis [20]. Thus, results here obtained support a potential pro-viral role of the SphK1/S1P axis in the replication of the RHDV virus, and

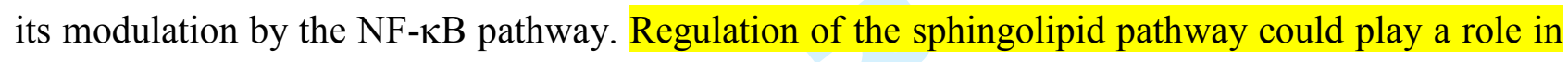
the inhibition of viral replication by melatonin, although other mechanisms previously reported to by modulated by the indole, such as decreased activity of antioxidant enzymes, activation of Nrf2 signaling and changes in the autophagic response may also make a significant contribution [26,27].

In conclusion, we here describe novel features of the SphK1/S1P axis within the liver, providing evidence that the hepatic SphK1/S1P system activates in rabbits experimentally infected with the RHDV and that inhibition of this signaling pathway by melatonin associates to an antiinflammatory effect and to a lowered RHDV replication induced by the indole. Melatonin has very high safety profile and no deaths or serious toxicity associated to its usage has been reported. Moreover, different studies have found melatonin being effective in fighting viral infections in a variety of experimental animal and in vitro studies [48,49]. Although further studies are required to 
a better knowledge of melatonin effects on virus-host interactions, data obtained reveal novel molecular pathways that may account for the protective effect of melatonin in virus-induced ALF, and support a possible therapeutical potential for melatonin in human virus-induced disorders.

\section{Acknowledgements}

DI. Sánchez is granted by AECC. CIBEREHD is funded by Instituto de Salud Carlos III, Spain.

\section{References}

1. MERRILL AH Jr. Sphingolipid and glycosphingolipid metabolic pathways in the era of sphingolipidomics. Chem Rev 2011; 111:6387-6422.

2. PITSON SM. Regulation of sphingosine kinase and sphingolipid signaling. Trends Biochem Sci 2011; 36:97-107.

3. SEO YJ, BLAKE C, ALEXANDER S, HAHM B. Sphingosine 1-phosphate-metabolizing enzymes control influenza virus propagation and viral cytopathogenicity. J Virol 2010; 84:8124-8131.

4. NAGAHASHI M, HAIT NC, MACEYKA M et al. Sphingosine-1-phosphate in chronic intestinal inflammation and cancer. Adv Biol Reg 2014; 54:112-120.

5. SPIEGEL S, MILSTIEN S. Sphingosine-1-phosphate: An enigmatic signalling lipid. Nat Rev Mol Cell Biol 2003; 4:397-407.

6. SANCHEZ T, HLA T. Structural and functional characteristics of S1P receptors. J Cell Biochem 2004; 92:913-922.

7. PYNE NJ, OHOTSKI J, BITTMAN R et al. The role of sphingosine-1-phosphate in inflammation and cancer. Adv Biol Reg 2014; 54:121-129. 
8. SERRIERE-LANNEAU V, TEIXEIRA-CLERC F, LI LY et al. The sphingosine 1-phosphate receptor S1P2 triggers hepatic wound healing. FASEB J 2007, 21:2005-2013.

9. LI C, YIANG X, YANG L et al. Involvement of sphingosine 1-phosphate (SIP)/S1P3 signaling in cholestasis-induced liver fibrosis. Am J Pathol 2009; 175:1464-1472.

10. IKEDA H, WATANABE N, ISHII I et al. Sphingosine 1-phosphate regulates regeneration and fibrosis after liver injury via sphingosine 1-phosphate receptor 2. J Lipd Res 2009; 50:556564.

11. XIU L, CHANG N, YANG L et al. Intracellular sphingosine 1-phosphate contributes to collagen expression of hepatic myofibroblasts in human liver fibrosis independent of its receptors. Am J Pathol 2015; 185:387-398.

12. GENG T, SUFFER A, HARLAND MD et al. SphK1 mediates hepatic inflammation in a mouse model of NASH induced by high saturated fat feeding and initiates proinflammatory signaling in hepatocytes. J Lipd Res 2015; 56:2359-2371.

13. CHEN J, WANG W, QI Y et al. Deletion of sphingosine kinase 1 ameliorates hepatic steatosis in diet-induced obese mice: Role of PPAR $\gamma$. Biochem Biophis Acta 2016; 1861:138-147.

14. MENDIZABAL M, SILVA MO. Liver transplantation in acute liver failure: A challenging scenario. World J Gastroenterol 2016; 22:1523-1531.

15. NGUYEN NT, VIERLING JM. Acute liver failure. Curr Opin Organ Transplant 2011; 16:289296.

16. YAMANE D, ZAHOOR MA, MOHAMED YM et al. Inhibition of sphingosine kinase by bovine viral diarrhea virus NS3 is crucial for efficient viral replication and cytopathogenesis. J Biol Chem 2009; 284:13648-13659.

17. WATI S, RAWLINSON SM, IVANOV RA et al. Tumor necrosis factor alpha (TNF- $\alpha)$ stimulation of cells with established dengue virus type 2 infection induces cell death that is 
accompanied by a reduced ability of TNF- $\alpha$ to activate nuclear factor $\kappa \mathrm{B}$ and reduced sphingosine kinase 1 activity. J Gen Virol 2011; 92:807-818.

18. MONICK MM, CAMERON K, POWERS LS et al. Sphingosine kinase mediates activation of extracellular signal-related kinase and Akt by respiratory syncytial virus. Am J Respir Cell Mol Biol 2004; 30:844-852.

19. MACHESKY NJ, ZHANG G, RAGHAVAN B et al. Human cytomegalovirus regulates bioactive sphingolipids. J Biol Chem 2008; 283:26148-26160.

20. SEO YJ, PRITZL CJ, VIJAYAN M et al. Sphingosine kinase 1 serves as a pro-viral factor by regulating viral RNA synthesis and nuclear export of viral ribonucleoprotein complex upon influenza virus infection. PLoS One 2013; 8:e75005.

21. VIJAYAN M, HAHM B. Influenza viral manipulation of sphingolipid metabolism and signaling to modulate host defense system. Scientifica 2014; 2014:793815.

22. SCHNEIDER-SCHAULIES J, SCHNEIDER-SCHAULIES S. Sphingolipids in viral infection. Biol Chem 2015; 396:585-595.

23. TUÑÓN MJ, SÁNCHEZ-CAMPOS S, GARCÍA FERRERAS J et al. Rabbit hemorrhagic viral disease: characterization of a new animal model of fulminant liver failure. J Lab Clin Med $2003 ; 141: 272-278$.

24. SAN-MIGUEL B, ÁLVAREZ M, CULEBRAS JM et al. N-acetyl-cysteine protects liver from apoptotic death in an animal model of fulminant hepatic failure. Apoptosis 2006; 11:19451957.

25. TUÑÓN MJ, SAN-MIGUEL B, CRESPO I et al. Melatonin attenuates apoptotic liver damage in fulminant hepatic failure induced by the rabbit hemorrhagic disease virus. J Pineal Res $2011 ; \mathbf{5 0 : 3 8 - 4 5 . ~}$ 
26. CRESPO I, SAN-MIGUEL B, LALIENA A et al. Melatonin prevents the decreased activity of antioxidant enzymes and activates nuclear erythroid 2-related factor 2 signaling in an animal model of fulminant hepatic failure of viral origin. J Pineal Res 2010; 49:193-200.

27. SAN-MIGUEL B, CRESPO I, VALLEJO D et al. Melatonin modulates the autophagic response in acute liver failure induced by the rabbit hemorrhagic disease virus. J Pineal Res 2014; 54:313-321.

28. MANCHESTER LC, COTO-MONTES A, BOGA JA et al. Melatonin: an ancient molecule that makes oxygen metabolically tolerable. J Pineal Res 2015; 57:403-419.

29. CHO SY, LEE HJ, JEONG SJ et al. Sphingosine kinase 1 pathway is involved in melatonininduced HIF-1alpha inactivation in hypoxic PC-3 prostate cancer cells. J Pineal Res 2011; 51:87-93.

30. TUÑÓN MJ, SAN-MIGUEL B, CRESPO I et al. Melatonin treatment reduces endoplasmic reticulum stress and modulates the unfolded protein response in rabbits with lethal fulminant hepatitis of viral origin. J Pineal Res 2013; 55:221-228.

31. MACAYKA M, HARIKUMAR KB, MILSTIEN H et al. Sphingosine-1-phosphate signaling and its role in disease. Trends Cell Biol 2012; 22:50-60.

32. TUÑÓN MJ, SAN-MIGUEL B, CRESPO I et al. Cardiotrophin-1 promotes a high survival rate in rabbits with lethal fulminant hepatitis of viral origin. J Virol 2011; 85:13124-13132.

33. TUÑÓN MJ, ÁlVAREZ M, CULEBRAS JM et al. An overview of animal models for investigating the pathogenesis and therapeutic strategies in acute hepatic failure. World $\mathrm{J}$ Gastroenterol 2009; 15:3086-3098.

34. LALIENA A, SAN-MIGUEL B, CRESPO, I et al. Melatonin attenuates inflammation and promotes regeneration in rabbits with fulminant hepatitis of viral origin. J Pineal Res 2012; 53:270-278. 
35. ZHANG T, YAN T, DUT et al. Apigenin attenuates heart injury in lipopolysaccharide-induced endotoxemic model by suppressing sphingosine kinase 1/sphingosine 1-phosphate signaling pathway. Chem Biol Interact 2015; 233:56-65.

36. LAI WQ, GOH HH, BAO Z et al. The role of sphingosine kinase in a murine model of allergic asthma. J Immunol 2008; 180:4323-4329.

37. CHOI JW, GARDELL SE, HERR DR et al. FTY720 (fingolimod) efficacy in an animal model of multiple sclerosis requires astrocyte sphingosine 1-phosphate receptor 1 (S1P1) modulation. Proc Natl Acad Sci USA 2011; 108:751-756.

38. VENEROSO C, TUÑÓN MJ, GONZÁLEZ-GALLEGO J et al. Melatonin reduces cardiac inflammatory injury induced by acute exercise. J Pineal Res 2009; 47:184-191.

39. ALVAREZ SE, HARIKUMAR KB, HAIT NC et al. Sphingosine-1-phosphate is a missing cofactor for the E3 ubiquitin ligase TRAF2. Nature 2010; 465:1084-1088.

40. WANG X, ZHANG DM, GU TT et al. Morin reduces hepatic inflammation-associated lipid accumulation in high fructose-fed rats via inhibiting sphingosine kinase 1/sphingosine 1phosphate signaling pathway. Biochem Pharmacol 2013; 86:1791-1804.

41. KANG JS, YOON YD, HAN MH et al. Glabridin suppresses intercellular adhesion molecule-1 expression in tumor necrosis factor-stimulated human umbilical vein endothelial cells by blocking sphingosine kinase pathway: implications of Akt, extracellular signal-regulated kinase, and nuclear factor-kappaB/Rel signaling pathways. Mol Pharmacol 2006; 69:941949.

42. HUANG K, LIU W, LAN T et al. Berberine reduces fibronectin expression by suppressing the S1P-S1P2 receptor pathway in experimental diabetic nephropathy models. PLoS One 2012; 7:E43874. 
43. YANG H, HREGGVIDSDOTTIR HS, PALMBLAD K et al. A critical cysteine is required for HMGB1 binding to Toll-like receptor 4 and activation of macrophage cytokine release. Proc Natl Acad Sci USA 2010; 107:11942-11947.

44. PCHEJETSKI D, NUNES J, COUGHAN H et al. The involvement of sphingosine kinase 1 in LPS-induced Toll-like receptor 4-mediated accumulation of HIF-1 $\alpha$ protein, activation of ASK1 and production of the proinflammatory cytokine IL-6. Immunol Cell Biol 2011; 89:268-274.

45. PUNEET P, YAP CT, LAM Y et al. SphK1 regulates proinflammatory responses associated with endotoxin and polymicrobial sepsis. Science 2010; 328:1290-1294.

46. CARR JM, MAHALINGAM S, BONDER CS et al. Sphingosine kinase 1 in viral infections. Rev Med Virol 2012; 23:73-84.

47. VIJAYAN M, SEO YJ, PRITZI CJ et al. Sphingosine kinase 1 regulates measles virus replication. Virology 2014; 450-451:55-63.

48. SILVESTEI M, ROSSI GA. Melatonin: its possible role in the management of viral infections. A brief review. Ital J Pediat 2013; 39:61.

49. TAN DX, KORKMAZ A, REITER R et al. Ebola virus disease: potential use of melatonin as a treatment. J Pineal Res 2014; 57:381-384. 


\section{Figure legends}

Fig. 1. Liver expression of SphK1 in RHDV-infected and melatonin-treated rabbits. (A): Photomicrographs of sections of liver samples taken from (a) Control; (b) Control + Mel; (c) RHDV 18 hr; (d) RHDV + Mel 18 hr; (e) RHDV 24 hr; (f) RHDV + Mel 24 hr; (g) RHDV 30 hr; (h) RHDV + Mel 30 hr; (i) RHDV 36 hr; (j) RHDV + Mel 36 hr. Paraffin-embedded sections were stained with SphK1 antibody. Original magnification: 200x. (B): Image analysis of the area of SphK1 staining. Image analysis was performed using the ImageJ software v3.91. (C): Levels of SphK1 mRNA analyzed by real-time PCR assay and normalized against $\beta$-Actin. (D): Western blot of SphK1. Proteins from liver extracts were separated by sodium dodecyl sulfate polyacrylamide gel electrophoresis, followed by immunoblotting. Equal loading of proteins is illustrated by $\beta$-Actin

bands. Values are expressed as means S.E.M $(n=6) . \stackrel{a}{p}<0.05$, compared with Control. $\stackrel{b}{p}<0.05$, compared with RHDV same period.

Fig. 2. Liver expression of S1PR1 in RHDV-infected and melatonin-treated rabbits. (A): Photomicrographs of sections of liver samples taken from (a) Control; (b) Control + Mel; (c) RHDV 18 hr; (d) RHDV + Mel 18 hr; (e) RHDV 24 hr; (f) RHDV + Mel 24 hr; (g) RHDV 30 hr; (h) RHDV + Mel 30 hr; (i) RHDV 36 hr; (j) RHDV + Mel 36 hr. Paraffin-embedded sections were stained with S1PR1 antibody. Original magnification: 200x. (B): Image analysis of the area of S1PR1 staining. Image analysis was performed using the ImageJ software v3.91. (C): Western blot of S1PR1. Proteins from liver extracts were separated by sodium dodecyl sulfate polyacrylamide gel electrophoresis, followed by immunoblotting. Equal loading of proteins is illustrated by $\beta$-Actin bands. (D): Level of S1P in rabbits liver homogenates analyzed by ELISA. Values are expressed as 
means S.E.M $(n=6) . \stackrel{a}{p}<0.05$, compared with Control. $\stackrel{b}{p}<0.05$, compared with RHDV same period.

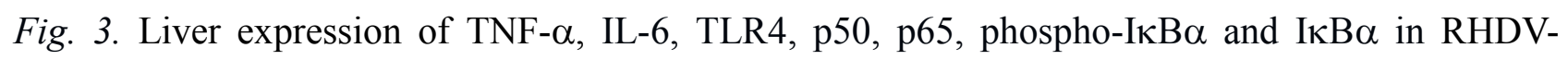
infected and melatonin-treated rabbits. Protein from liver extracts was separated by sodium dodecyl sulfate-polyacrylamide gel electrophoresis, followed by immunoblotting. Equal loading of proteins is illustrated by $\beta$-Actin bands. Left upper panel shows representative Western-blot photographs. Histograms represent the result of densitometric quantification. Values are expressed as means S.E.M (n=6). $\stackrel{\mathrm{a}}{\mathrm{p}}<0.05$, compared with Control. $\stackrel{\mathrm{b}}{\mathrm{p}}<0.05$, compared with RHDV same period.

Fig. 4. Liver expression of the RHDV capsid protein VP60 in RHDV-infected and melatonintreated rabbits. (A): Photomicrographs of sections of liver samples taken from (a) Control, (b) Control + Mel (c) RHDV 18 hr; (d) RHDV + Mel 18 hr; (e) RHDV 24 hr; (f) RHDV + Mel 24 hr; (g) RHDV 30 hr; (h) RHDV + Mel 30 hr; (i) RHDV 36 hr. (j) RHDV + Mel 36 hr. Paraffinembedded sections were stained with VP60 antibody. Original magnification: 200x. (B): Image analysis of the area of VP60 staining. Image analysis was performed using the ImageJ software v3.91. Values are expressed as means S.E.M $(n=6) . \stackrel{a}{p}<0.05$, compared with Control. ${ }^{b} p<0.05$, compared with RHDV same period. 


\section{Page 21 of 24}

A

1

2

3

4

5

6

7

8

9

10

11

12

13

14

15

16

17

18

19

20

21

22

23

24

25

26

27

28

29

30

31

32

33

34

35

36

37

38

39

40

41

42

43

\section{Journal of Pineal Research}
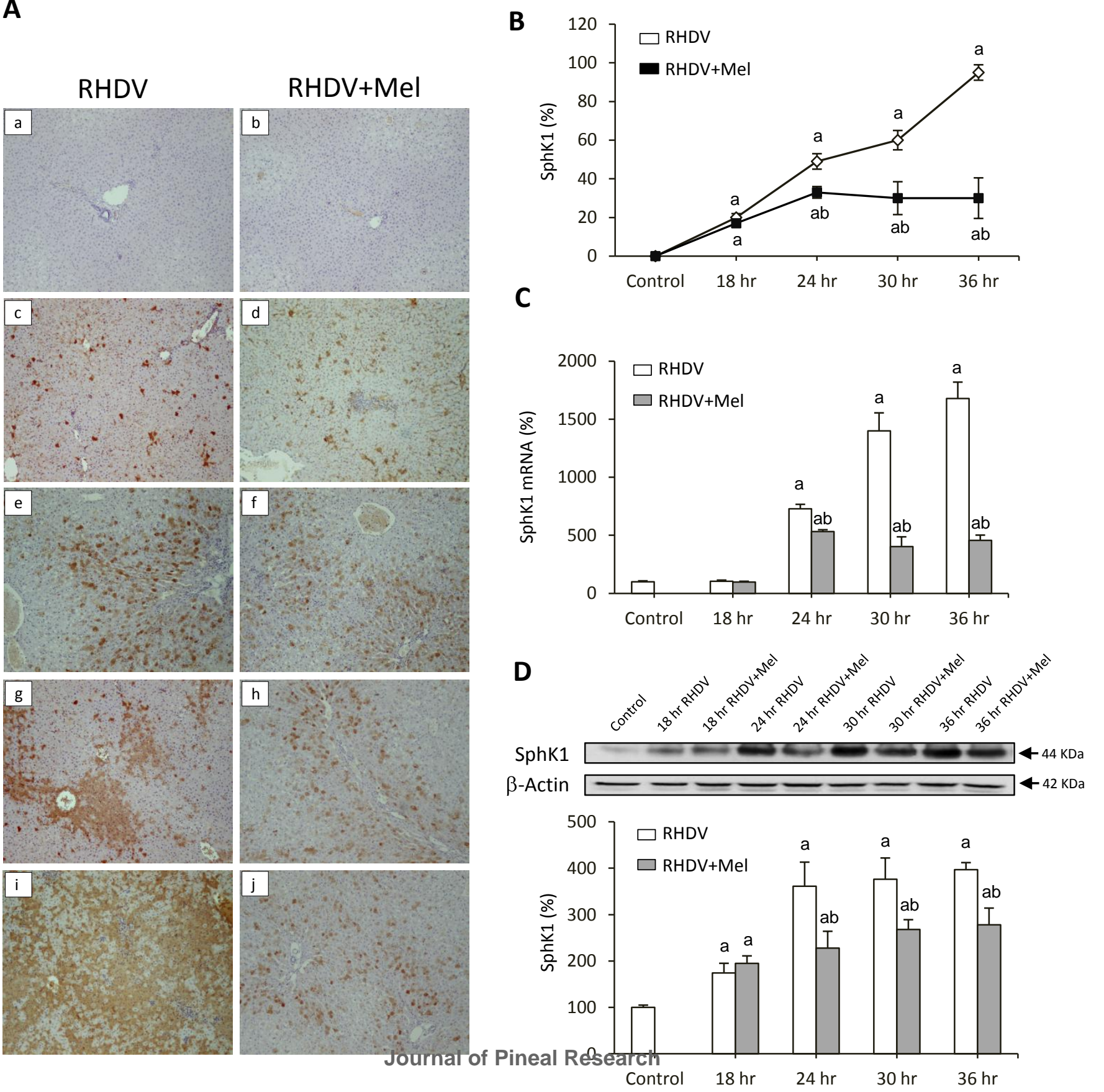


\section{Journal of Pineal Research}

A

1

2

3

4

5

6

7

8

9

10

11

12

13

14

15

16

17

18

19

20

21

22

23

24

25

26

27

28

29

30

31

32

33

34

35

36

37

38

39

40

41

42
B 100
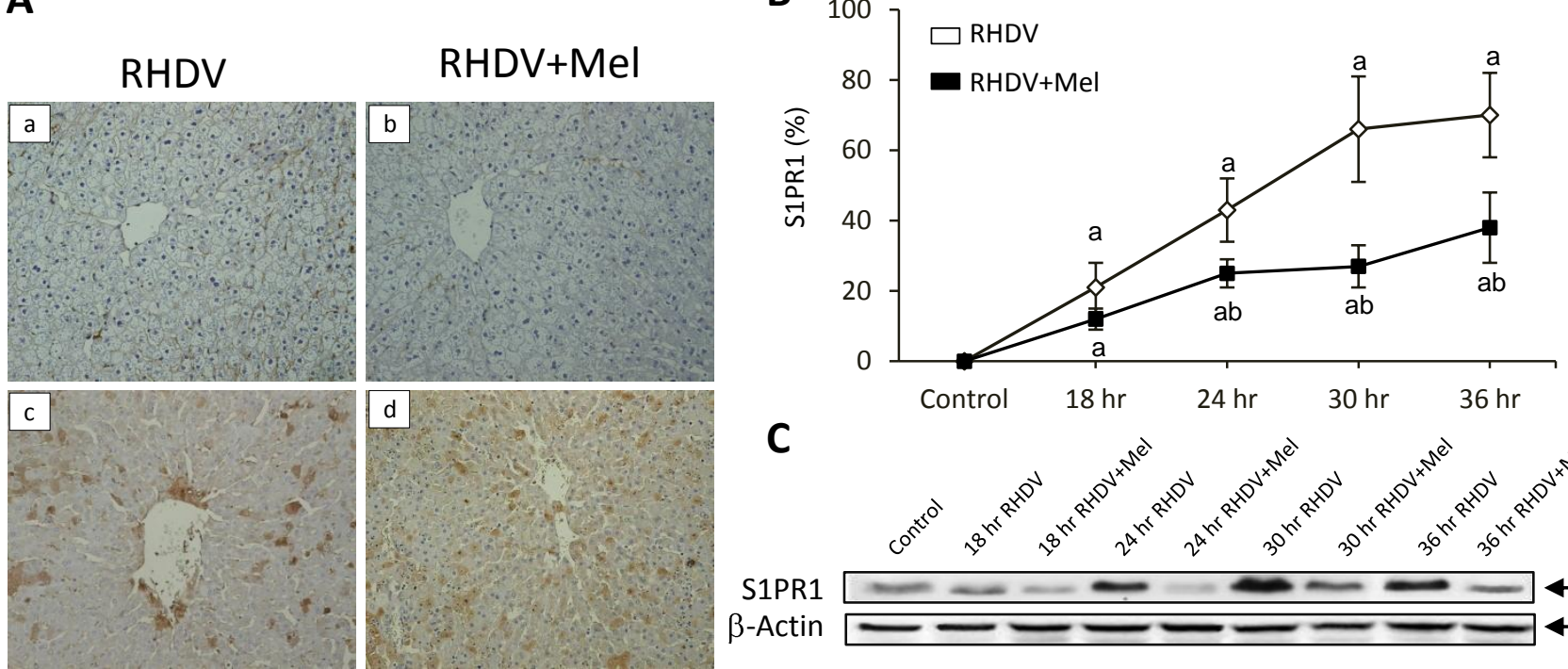

C

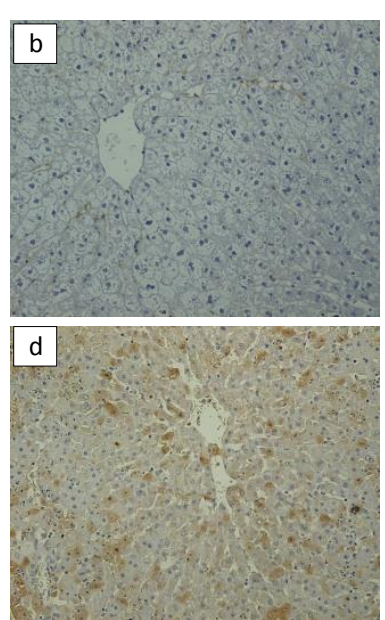

S1PR1

$\beta$-Actin
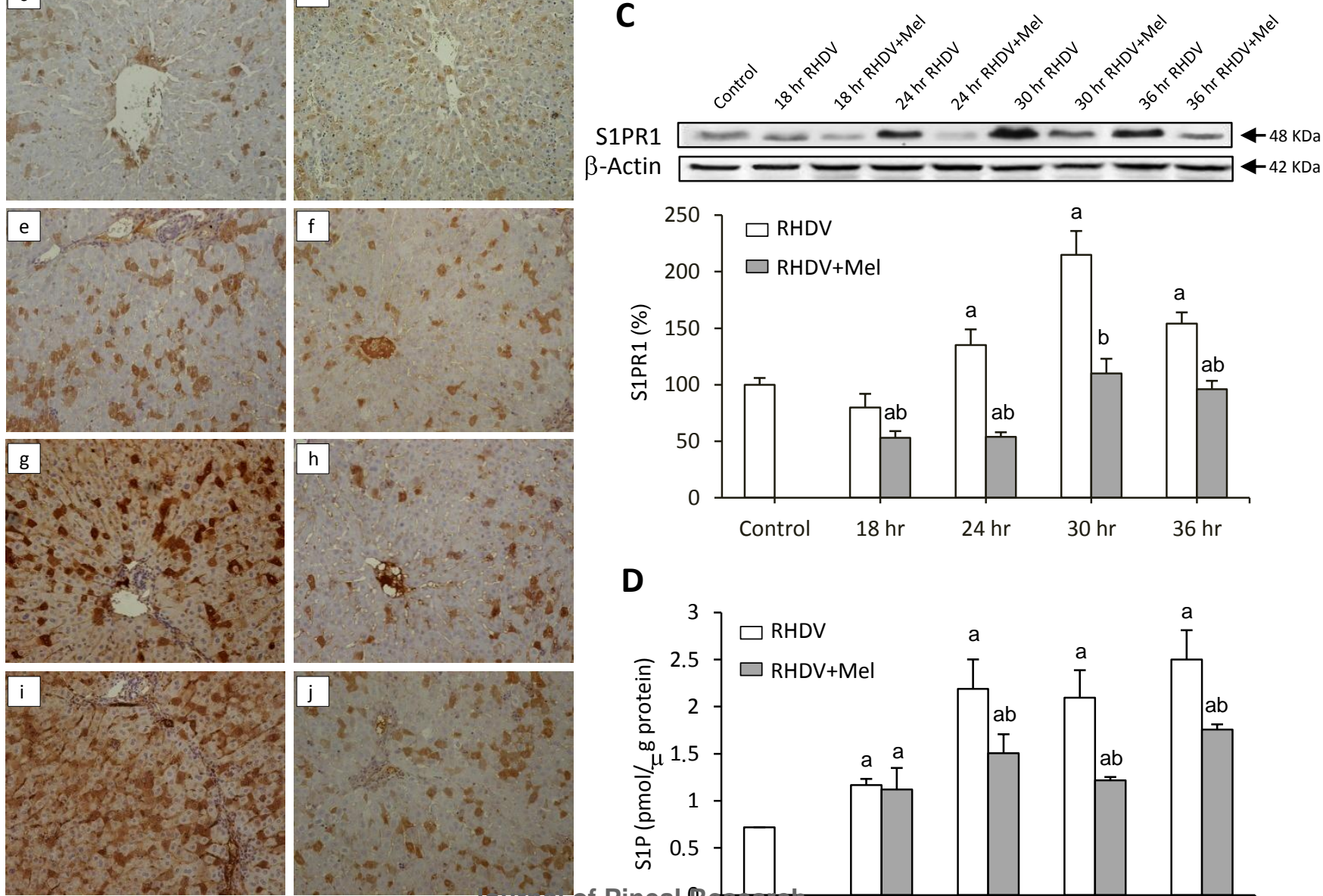

D

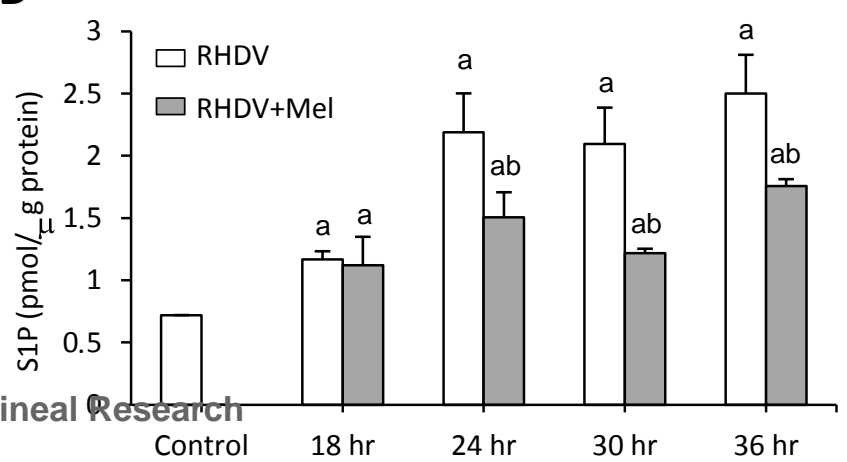




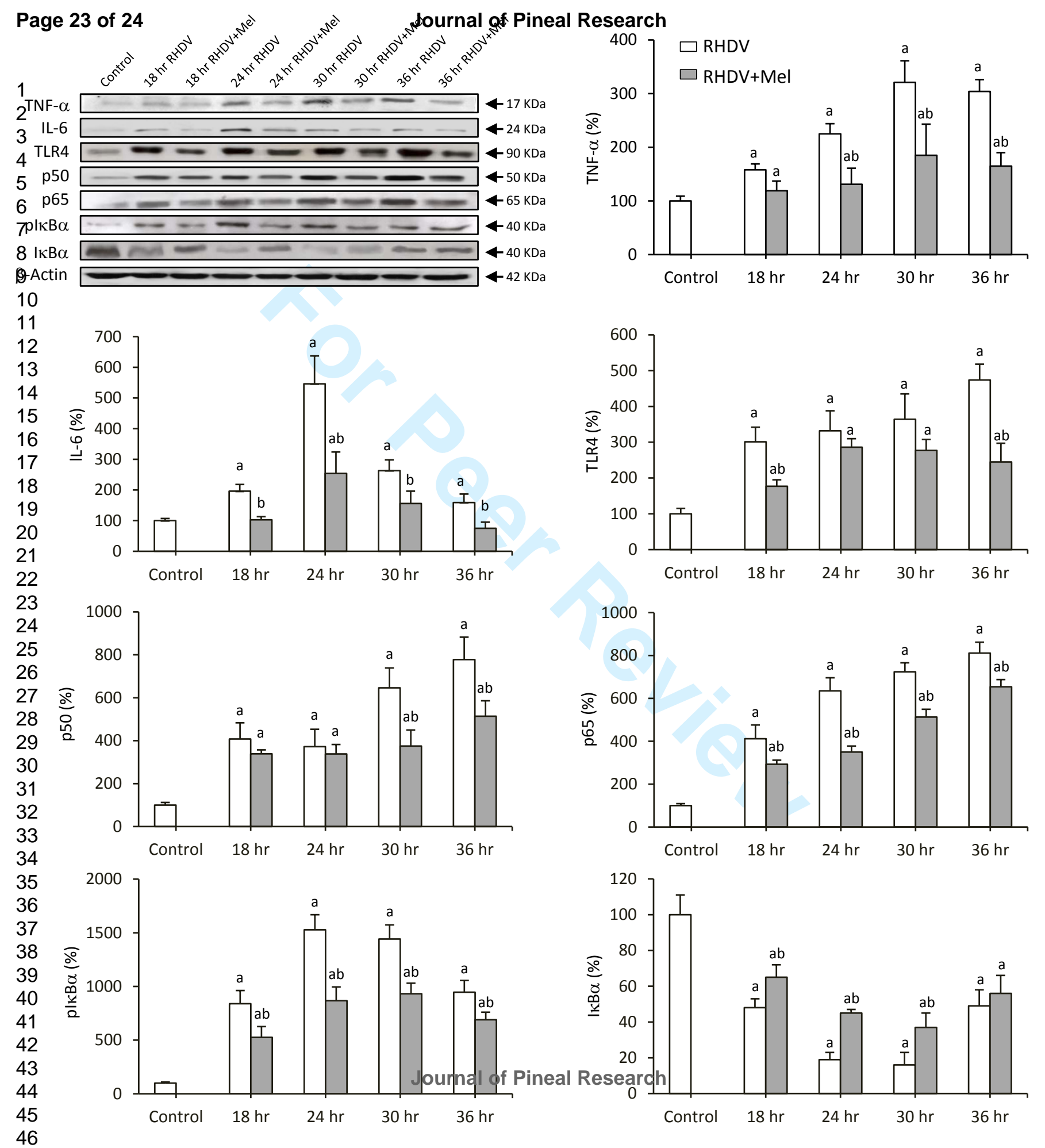




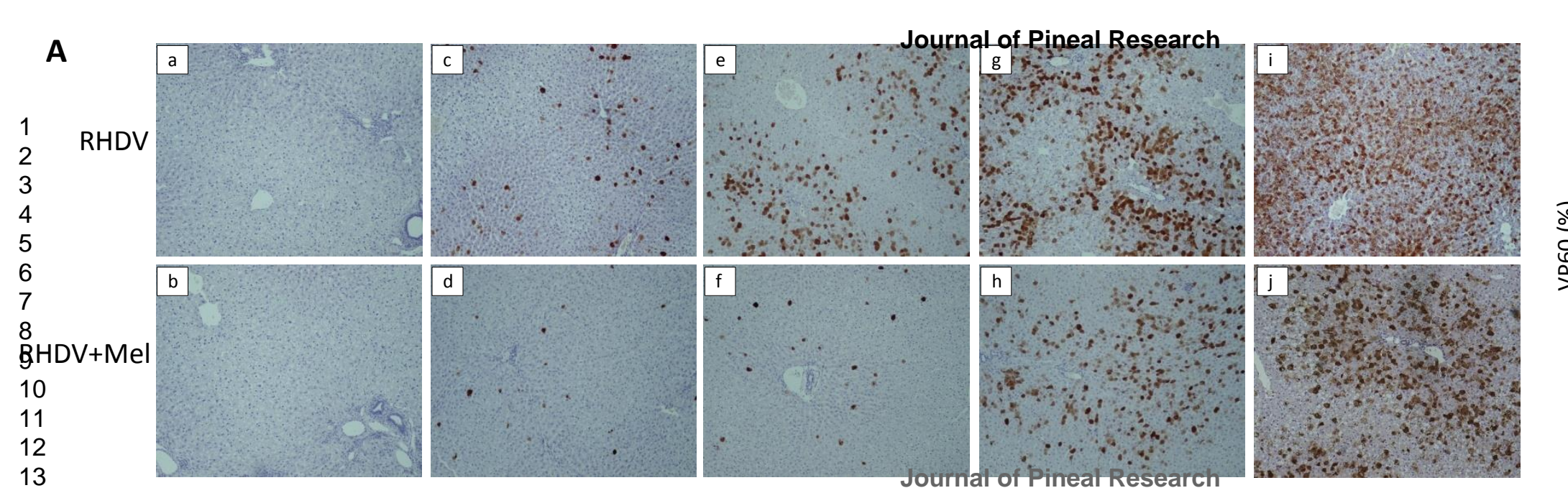

\section{Page 24 of 24}

B

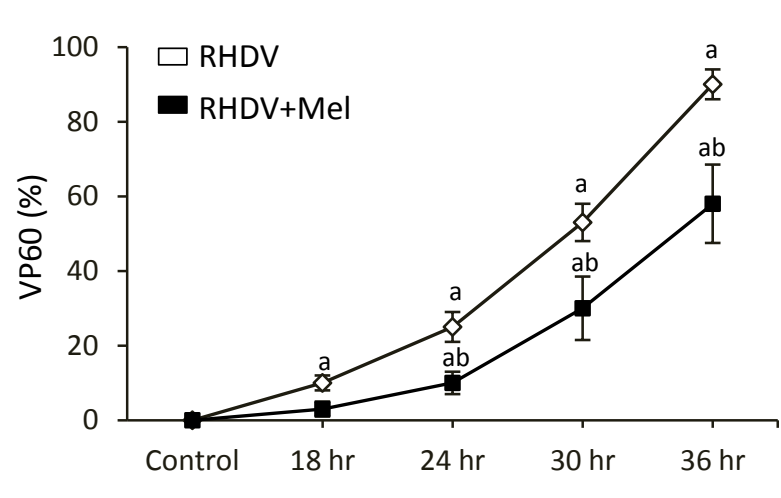

